\title{
Propuesta didáctica para el aprovechamiento educativo de la visita a un parque temático y generar actitudes positivas hacia el aprendizaje de las ciencias ${ }^{1}$
}

Germán Londoño Villamil ${ }^{2}$ Jordi Solbes Matarredona ${ }^{3}$ Ana Patricia León Urquijo ${ }^{4}$

\begin{abstract}
Resumen
Este artículo presenta las estrategias didácticas que utilizaron los profesores de secundaria de ciencias del Colegio Santa Teresa de Jesús del municipio de Armenia para el aprovechamiento didáctico del Parque Nacional de la Cultura Agropecuaria - Panaca antes, durante y después de las visitas con los diferentes grupos de estudiantes de la educación básica secundaria y media vocacional, con el propósito de generar actitudes positivas hacia el aprendizaje de ciencias naturales. Se presentan las estrategias didácticas preinstruccionales: dos pretest de actitudes (cuidado del ambiente y actividades agrarias), los objetivos correspondientes a los ítems de los pretest. Las estrategias didácticas coinstruccionales en el ambiente no formal, donde los estudiantes observaron, recolectaron la información directamente en la visita y procesaron la información en el ambiente formal del aula de clase. Las estrategias didácticas posinstruccionales en ambiente formal y no formal, la comparación de los resultados y la aplicación de los postest de actitudes. Finalmente, los resultados de la experiencia y las conclusiones.
\end{abstract}

\section{Palabras clave:}

Estrategia, didáctica, ciencias, aprendizaje, actitudes, ambiente, formal, no formal, actividades, agraria.

\section{Abstract}

This article presents teaching strategies used teachers of secondary the College Santa Teresa of Jesus of the municipality of Armenia, training national culture agricultural Panaca before, during and after visits with

1 Este artículo se basa en la tesis doctoral realizada por Germán Londoño Villamil en el Departamento de Didáctica de las Ciencias Experimentales y Sociales de la Universitat de València - España (leída el 23 de julio de 2009)

2 Doctor en Ciencias Biológicas. Director de Administración Ecoturística y Hotelera, Escuela de Administración y Mercadotecnia del Quindío, Armenia. lonviger@alumni.uv.es

3 Doctor en Ciencias Físicas. Profesor del Departamento de didáctica de las Ciencias Experimentales y Sociales de la Universitat de València España. jordi.solbes@uv.es

4 Doctora en Filosofía y Ciencias de la Educación. Profesora titular de la Universidad del Quindío. apleon@uniquindio.edu.co 
different groups of students of secondary education and vocational average Park use science to generate positive towards natural sciences learning attitudes. Preinstruccionals teaching strategies are presented in the formal environment: two pre-test of attitudes (care for the environment and farming), the relevant items of the pre-test goals. Coinstruccionals in the non-formal atmosphere where students observed, didactic strategies collected information directly in the visit and processed information in the formal atmosphere of the classroom class. Postinstruccional formal atmosphere and non-formal, comparison of results and the application of the post-test of attitudes didactic strategies. Finally experience results and conclusions.

\section{Key words:}

Strategy, didactics, sciences, learning, attitudes, ambient, formal, non-formal activities, land.

\section{Introducción T1}

Este trabajo se inicia a partir de los resultados de un estudio del aprovechamiento conceptual y actitudinal de las visitas al Parque Nacional de la Cultura Agropecuaria - Panaca, que se realizó sin aviso previo a los estudiantes y profesores (Londoño et ál., 2009). Se encontró que muy pocos profesores mostraron interés en elaborar las guías didácticas para la visita. Además, un bajo porcentaje de los mismos aprovecharon los elementos didácticos de la temática del parque para el desarrollo de temas en las ciencias naturales. Las pocas actividades que los estudiantes realizaron después de la visita a Panaca demuestran que la mayoría fue de paseo, para cambiar de ambiente y pasar un rato agradable, y que las actividades carecieron de profundidad y relación con el aprendizaje de las ciencias donde se hubiese podido realizar una mejor utilización de los aspectos del parque temático. Sin embargo, y esto nos hace ser optimistas, los estudiantes recuerdan aspectos puntales diferenciados asociados a las impresiones y experiencias vividas en el Parque. Esto implica que los conocimientos adquiridos a través de la acción directa, de forma relajada y divertida, que- dan muy fijados en su mente y pueden recordarlos con facilidad.

A partir de este diagnóstico, nos planteamos el objetivo de optimizar el uso y aprovechamiento didáctico de la temática tratada en el Parque Nacional de la Cultura Agropecuaria - Panaca para mejorar el aprendizaje y generar actitudes positivas hacia las ciencias naturales en los estudiantes. En el trabajo se presentan algunos resultados debidos a las estrategias didácticas que se diseñaron con los profesores para la visita a - Panaca, obtenidos con estudiantes de secundaria de $6^{\circ}$ a $11^{\circ}$, que no conocían el Parque, que nos permitirán comprobar si se cambian las actitudes de los estudiantes respecto al cuidado del medioambiente y la actividad agraria. Dichas estrategias pretendían desarrollar en los estudiantes la motivación para observar, experimentar, indagar, consultar, preguntar, analizar, interpretar y criticar, tanto en ambientes formales como no formales, de tal forma que se logren actitudes positivas hacia las ciencias.

\section{Marco teórico}

\section{La generación de actitudes positivas hacia el aprendizaje de las ciencias}

Dada la complejidad del concepto de actitud, conviene clarificarlo y conocer sus dimensiones. Así, las actitudes propiamente dichas (o su componente conductual) se refieren a reglas o patrones de conducta, disposiciones a comportarse de modo consistente. El conocimiento de las normas (o el componente cognitivo) estaría constituido por las ideas o creencias sobre cómo hay que comportarse. Y, finalmente, los valores (dimensión afectiva) se referirán al grado en que se han interiorizado los principios que rigen el funcionamiento de esas normas (Ponce, 1981; Summers, 1986; Pozo y Gómez, 1998). Aunque la dimensión cognitiva de las actitudes y las normas puede enseñarse y aprenderse como un contenido verbal más, su aceptación afectiva y conductual, su conversión en valores y actitudes propiamente dichas requiere mecanismos de aprendizaje específicos (Solbes, 2009). 
Gardner (1996) distingue entre los intereses por la ciencia, las actitudes hacia los científicos y hacia el uso de la ciencia. Hodson (1985) habla de actitudes hacia la ciencia y su imagen pública, hacia los métodos de la ciencia, actitudes sobre las "actitudes científicas" (entendidas como adhesiones personales a estas actitudes), actitudes sobre las implicaciones sociales y ambientales de la ciencia y actitudes hacia la enseñanza de las ciencias.

Fensham (2004) afirma que el principal problema de la enseñanza de la ciencia (y, por tanto, de la investigación en didáctica de la ciencia) son las actitudes negativas de los estudiantes y su falta de interés hacia su aprendizaje en la escuela. La curiosidad y el interés natural de los niños hacia la ciencia comienzan a transformarse en desinterés, aburrimiento y experiencias de fracaso escolar (Murphy y Beggs, 2003). Generalmente, en la niñez se tienen actitudes favorables y una gran curiosidad sobre la Ciencia y Tecnología, que va decreciendo con la edad de los estudiantes, especialmente en algunas materias como Física y Química, particularmente en las mujeres (Osborne et ál., 1998; Simpson y Troots, 1982; Solbes y Vilches, 1989 y 1997). Algunos trabajos puntualizan específicamente que esta erosión de las actitudes hacia la ciencia, admitida y confirmada en secundaria, incluso podría empezar al final de la educación primaria (Murphy y Beggs, 2003). Y, por último, en trabajos recientes se constata que ese desinterés ha aumentado (Solbes et ál., 2007; Vázquez y Manassero, 2008).

Para que el estudiante adquiera actitudes positivas hacia el aprendizaje de las ciencias naturales se requiere facilitar el aprendizaje para que se crea capaz de comprenderla y aprobarla, y así este motivado para aprenderla. Para ello, el profesor está motivado, preparado e identificado con el trabajo. Es importante que se lleve una secuencia, tutoría, así como un acompañamiento al estudiante durante sus niveles académicos, motivándolos a lograr ese descubrimiento permanente. Por otra parte, diversas investigaciones han mostrado cómo la introducción de actividades de ciencia, tecnología, sociedad y ambiente (CTSA), y de historia de las ciencias pueden contribuir a cambiar la actitud negativa de los estudiantes hacia las ciencias, aumen- tando su interés (Solbes y Vilches, 1997; Solbes y Traver, 2003). Esto se puede conseguir con otros recursos: experiencias y juguetes tecnocientíficos, los museos, las TIC, etc. (Guisasola y Morentin, 2007; Guisasola et ál., 2009; Pro, 2005; Solbes et ál., 2008). En cambio, sólo la educación CTSA contribuye a una imagen más completa y contextualizada de las ciencias.

Por último, en cuanto a las actitudes negativas hacia la ciencia de las chicas (Simpson et ál., 1994), para cambiarlas se requiere tener en cuenta los intereses y necesidades de los estudiantes. En Panaca se observa un interés por conocer y aprender para aplicar estos beneficios, en especial a las mujeres; ellas preguntaban sobre si podrían utilizar estas plantas en el jardín de la casa para lograr repeler los insectos peligrosos para la salud, teniendo en cuenta que en esa región existen enfermedades causadas por diferentes insectos. Las actitudes positivas hacia el aprendizaje de las ciencias se ven beneficiadas con estas unidades.

\section{Estrategias didácticas para generar actitudes positivas hacia el aprendizaje de la ciencia}

Las actitudes positivas hacia la ciencia se conforman a partir de la interacción del sujeto con su ambiente, y como ese sujeto es sociable por naturale$\mathrm{za}$, estas interacciones positivas o negativas son las que inciden en la calidad de vida de la población (León et ál., 2006). Las actitudes conforman sus características en función de la información recibida. Una actitud se transforma cuando hay un cambio cualitativo con respecto al objeto de una actitud previamente existente (Ponce, 1981). Es decir, si para los estudiantes no era de interés la actividad agraria de la región y cuidar el ambiente próximo, la visita programada y motivada a Panaca (ambiente no formal), así como la posterior realimentación sobre los temas allí vistos y tratados en el ambiente formal, permitirá generar en los estudiantes actitudes positivas hacia estos aspectos.

Para lograr en los estudiantes actitudes positivas hacia el aprendizaje de las ciencias se requiere que el profesor diseñe estrategias didácticas que les 
permitan ver las ciencias atractivas, que encuentren significado y utilidad en la vida práctica, y es la educación en contextos no formales en el campo, en los museos de ciencias y en los parques temáticos donde se encuentran ambientes propicios para aprendizajes duraderos que se refuerzan en los contextos formales, siempre y cuando el profesor planee estrategias didácticas antes, durante y después de las visitas a estos escenarios.

Las estrategias de enseñanza en los contextos formales y no formales se pueden definir como procedimientos o recursos utilizados por el profesor para promover aprendizajes significativos en los estudiantes. En el caso específico de estrategias para el aprendizaje significativo en ambiente no formal, el profesor puede utilizarlas antes de la visita (preinstruccionales), durante la visita (coinstruccionales) o después de la visita (posinstruccionales) de un contenido curricular específico.

En las estrategias preinstruccionales el profesor prepara las recomendaciones generales, valora el sitio, bien sea directamente o por Internet, prepara el tratamiento didáctico de la visita al parque temático como ambientes de aprendizaje (Lillo, 2002) dentro del aula, en el ambiente formal; ubica al estudiante en el qué y cómo se va a aprender, es decir, activa el conocimiento y las experiencias previas, que le permiten ubicarse en el contexto del aprendizaje pertinente, algunas de estas estrategias son los objetivos o propósitos de aprendizaje y los organizadores previos. Esa labor del profesor ha de ser consecuencia de una minuciosa y elaborada programación, para tal fin ha de estar preparado a fin de afrontar un aprendizaje continuo, no solamente en lo referente a los contenidos de su asignatura, sino también en todos aquellos otros aspectos sociales que tienen repercusión en la educación (Bujeda et ál., 2004). De esta forma, antes de la visita al parque temático el estudiante se motiva y va con la disposición para observar, preguntar, comprender y aprender. La voluntad del estudiante es indispensable para el aprendizaje y la formación de actitudes positivas hacia la ciencia. El profesor, además, presenta a los estudiantes una guía o cuestionario, el cual analizan y acuerdan la forma de diligenciarlo.
En las estrategias didácticas preinstruccionales es prudente incluir la manera como se genera el conocimiento, y los objetivos que se pretenden alcanzar, incorporando nuevos contenidos de una temática concreta y de forma coherente, generando asimismo contenidos bien estructurados, que preparan una base amplia para la elaboración de materiales útiles y acordes con la argumentación teórica $(\mathrm{Bu}-$ jeda et ál., 2004).

Las estrategias coinstruccionales, experiencias directas, ilustraciones, redes semánticas, pistas tipográficas y discursivas, mapas conceptuales y analogías (Díaz y Hernández, 1998), apoyan los contenidos curriculares dentro del proceso en el ambiente no formal (parque temático). También, "las capacidades básicas relacionadas con la metodología científica, tales como las de observación, clasificación, medición, obtención precisa de los datos, interpretación de los mismos" (Lillo y Lillo, 2002); la interacción con la temática del parque mantiene la atención y la motivación, el estudiante experimenta, resuelve, pregunta, analiza, comprende, cuestiona información principal, conceptualiza contenidos, delimita la organización, la estructura y las interrelaciones entre los mismos contenidos, recopila información para resolver las preguntas de la guía o cuestionario.

Las estrategias posinstruccionales, pospreguntas intercaladas, resúmenes finales, redes semánticas y mapas conceptuales (Díaz y Hernández, 1998), se utilizan después de la visita en ambiente formal; allí se analiza la información recolectada, el contenido aprendido, y se permite que el estudiante forme una visión sintética, integradora y crítica del material, permitiendo a su vez evaluar el propio aprendizaje. El profesor utiliza la temática de la visita en el desarrollo de temas específicos, hace referencia a aspectos puntuales, promueve la evocación de los estudiantes, compara lo observado y experimentado con los textos, realiza análisis crítico, deduce y aclara dudas.

En las interacciones que se establecen en los ambientes educativos formales y no formales, los parques temáticos son escenarios que permiten aportaciones al proceso de enseñanza/aprendizaje, contribuyen al 
trabajo del aula, de tal forma que el profesor y los estudiantes intercambian sus experiencias antes, durante y después de las visitas guiadas en un tema o temas determinados del currículo educativo.

\section{Diseño metodológico para la educación de las actitudes positivas hacia el aprendizaje de las ciencias}

En el diseño metodológico para el aprovechamiento didáctico de un parque temático se tuvieron en cuenta los objetivos y su conexión con los posteriores instrumentos de investigación (pretest, postest), y las estrategias didácticas para los profesores antes, durante y después de las visitas al parque temático Panaca con los diferentes grupos.

\section{Objetivos del aprovechamiento didáctico del parque temático Panaca, cuidado del ambiente y actividad agraria}

Se plantean los objetivos para las estrategias didácticas antes durante y después de la visita, preparadas por equipos de profesores y realizadas por los estudiantes en Panaca (cuadros 1 y 2). Tales objetivos están basados en los objetivos curriculares de Ciencias, trazados por el Ministerio de Educación Nacional para los grados $6^{\circ}$ a $11^{\circ}$ de bachillerato (edades de los 11 a los 18 años), y se ha tenido en cuenta, particularmente, el siguiente objetivo: "Argumentar con honestidad y sinceridad a favor o en contra de teorías, diseños experimentales, conclusiones y supuestos en un ambiente de respeto por la persona”.

\section{CUADR0 1. Cuidado del ambiente}

Objetivo general. Cuidar de las plantas nativas, ornamentales y alimenticias.

Objetivos específicos

Indagar sobre las plantas nativas y alimenticias de la región promoviendo su cuidado y previniendo su extinción.

Comprender la importancia de las cuatro R ecológicas -reciclar, reducir, reorganizar y reutilizar- en las prácticas del separado de los residuos sólidos, líquidos, gaseosos, coloidales y peligrosos, manteniendo concienciación en las prácticas limpias de la separación de desechos con usos adecuados de los contenedores de desechos, recicles y basuras.

Promover programas con campañas para el cuidado de las especies vegetales y la siembra de plantas ornamentales, tanto en el colegio como en la casa.

Tener conciencia de no arrojar desechos inorgánicos en el medio natural, aguas y naturaleza en general, y lograr integrarse a grupos ambientalistas para adelantar actividades y proyectos de prevención en el uso y abuso de pesticidas, plaguicidas entre otros es un principio con el que se motiva a los estudiantes, se les fomentan las actividades orgánicas evitando el mal uso de los ríos y las quebradas por la acción de los residuos inorgánicos.

Conocer la importancia de reforestar y sembrar especies que no alteren el equilibrio del medioambiente y que mantengan los ecosistemas donde se desarrollan.

Indagar sobre tratamientos de las aguas residuales, procesos del café y sus residuos inorgánicos, prevención de incendios forestales, especies vegetales y animales nativas de la región y su contribución al ciclo de vida de los seres humanos. Conocer qué se hace con los residuos orgánicos de las especies vegetales y animales que se utilizan para el procesamiento de alimentos.

Objetivo general. Cuidar de los animales domésticos, nativos y silvestres.

Indagar sobre los animales nativos permite comprender el ciclo de la vida, pero además se generan actitudes positivas hacia la conservación de esas especies. 
CUADR0 2. Actividades agrarias

\begin{tabular}{|l|}
\hline Objetivo general. Determinar las relaciones entre los seres vivos. \\
\hline Objetivos específicos \\
\hline $\begin{array}{l}\text { Conocer y comprender los ciclos de vida de los animales y vegetales en relación con los seres humanos, logran- } \\
\text { do la toma de conciencia hacia el respeto por los animales y su entorno. }\end{array}$ \\
\hline $\begin{array}{l}\text { Diferenciar los alimentos que consumen los seres humanos y su forma de procesarlos con un enfoque claro hacia } \\
\text { lo orgánico-natural. }\end{array}$ \\
\hline $\begin{array}{l}\text { Aprender a consumir alimentos naturales y tener una dieta diaria balanceada apoyada por los consejos dados en } \\
\text { el programa de comunicación del colegio. }\end{array}$ \\
\hline $\begin{array}{l}\text { Estar informado acerca de las enfermedades causadas por la carencia del consumo de alimentos tales como } \\
\text { frutas y verduras. }\end{array}$ \\
\hline $\begin{array}{l}\text { Evitar la convivencia con animales salvajes, fomentando el uso y mantenimiento solo de animales domésticos } \\
\text { como mascotas, conociendo su hábitat y defendiendo el buen trato. }\end{array}$ \\
\hline $\begin{array}{l}\text { Tener noción y conocimiento del entorno que nos rodea, incluidas las actividades agrarias y la influencia de estas } \\
\text { en el quehacer diario. }\end{array}$ \\
\hline $\begin{array}{l}\text { Reconocer alternativas como la agricultura ecológica ante el efecto perjudicial de los fungicidas químicos tanto } \\
\text { para los animales como para los humanos. }\end{array}$ \\
\hline
\end{tabular}

Con base en los objetivos planteados se elaboran las preguntas de los cuestionarios realizados a varios grupos de estudiantes en diferentes grados académicos, para detectar sus cambios actitudinales con respecto al medioambiente y a las actividades agropecuarias de su entorno que veremos a continuación, así como las estrategias didácticas para la visita al Parque.

\section{Pretest de actitudes del aprendizaje de las ciencias}

Para conocer las actitudes de los estudiantes frente a las ciencias y su aprendizaje, se diseñaron dos pretest de actitudes: uno de cuidado del ambiente y otro sobre la actividad agraria, los cuales contestaron los estudiantes antes de una visita planeada por los profesores a Panaca.

El pretest de actitudes es una prueba para medir diversas facultades intelectuales del individuo, en este caso las actitudes que tienen los estudiantes de $6^{\circ}$ a $11^{\circ}$ de la educación formal, frente a las ciencias en el ambiente (cuadro 3) y la actividad agraria (cuadro 4), teniendo en cuenta los conocimientos previos o preconceptos aprendidos en los ambientes familiar, escolar y social. Los pretest de actitudes se utilizan porque permiten establecer una información más clara y concreta, ya que se presentan las afirmaciones o los enunciados que el estudiante debe señalar según las valoraciones utilizadas: Estoy muy de acuerdo, Estoy de acuerdo, Me es indiferente, Estoy en desacuerdo y Estoy muy en desacuerdo, elementos del modelo de Fishbein-Ajzen (1980). Este modelo plantea la predicción del cambio de conducta mediante la modificación de las creencias o la base informativa que precede a las actitudes y normas subjetivas, que condicionan y determinan la intención de conducta y la conducta misma. Los pretest se validaron mediante pruebas piloto a estudiantes de $6^{\circ}$ a $11^{\circ}$ grado de la educación básica y media vocacional del sector oficial, que no participaron en esta investigación. 


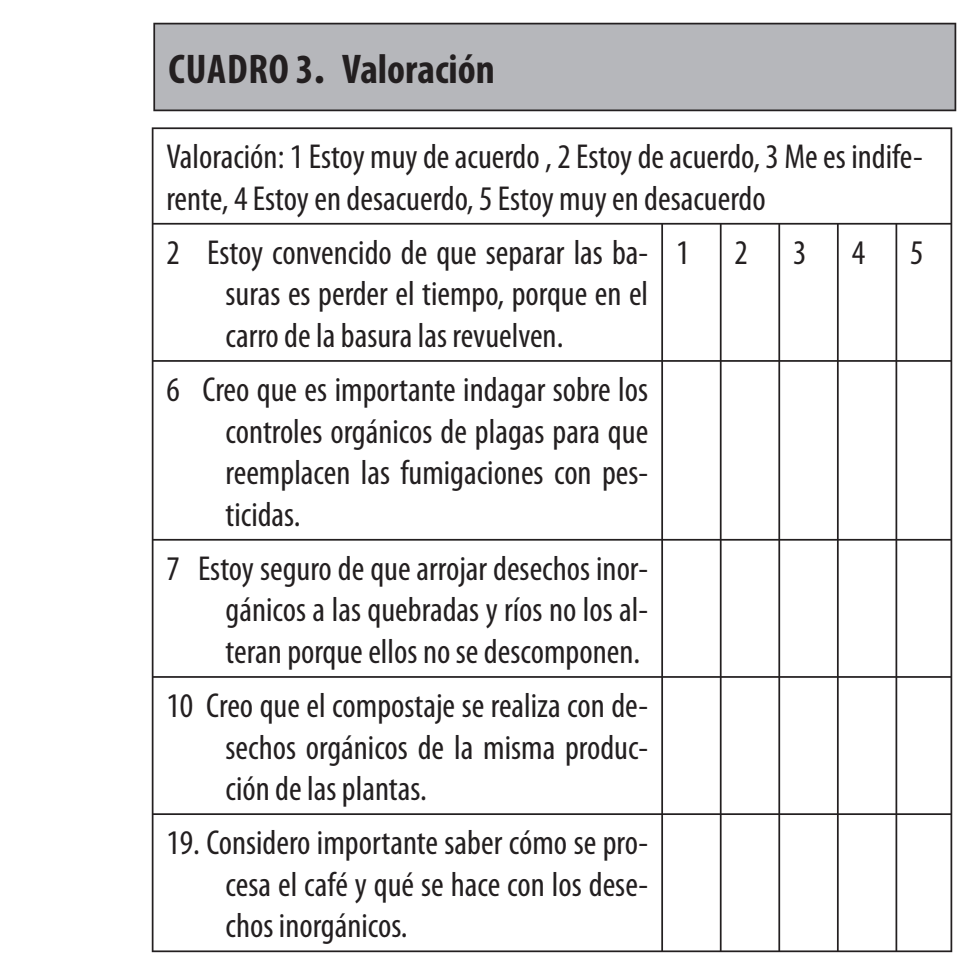

CUADRO 4. Valoración

Valoración: 1 Estoy muy de acuerdo, 2 Estoy de acuerdo, 3 Me es indiferente, 4 Estoy en desacuerdo, 5 Estoy muy en desacuerdo

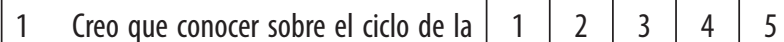
vida de los animales y vegetales es importante para comprender la relación entre ellos y nosotros.

5 Creo que conocer sobre la forma de procesar los alimentos provenientes de los animales y los vegetales influye en que obtenga buenas calificaciones en ciencias naturales.

6 Pediré información a los profesores sobre la elección de los productos alimenticios provenientes de los animales y los vegetales de consumo humano.

10 Creo que conocer sobre el cuidado y la reproducción de los animales domésticos me permitirá comprender la importancia de ellos en la supervivencia de los seres humanos.

15 Las enfermedades de los animales que se utilizan para el consumo no afectan la salud humana.

19 Creo que conocer sobre la forma en que se procesan los productos animales y vegetales me permitirá elegir cuáles consumo.
En el cuadro 3 presentamos algunos ítems seleccionados del pretest sobre el cuidado del ambiente.

En el cuadro 4 presentamos algunos ítems seleccionados del pretest sobre actividades agrarias.

\section{Estrategias didácticas antes de la visita al parque temático Panaca}

Las estrategias didácticas preinstruccionales permiten, en el ambiente formal del aula, ubicar al estudiante en qué y cómo aprender, y activan el conocimiento y las experiencias previas (Ausubel et ál., 1983) con respecto a las ciencias naturales. Las estrategias preinstruccionales fueron: el desarrollo de objetivos o propósitos de aprendizaje, el conocimiento que tenían los profesores acerca del parque, los pretest de actitudes hacia el ambiente y la actividad agraria, la guía o cuestionario que motiva y dispone la voluntad del estudiante para observar, preguntar, comprender y aprender las ciencias naturales propias de Panaca.

Se diseñaron tres guías: a) para los grados $6^{\circ}, 7^{\circ}$ y $8^{\circ}$ (estudiantes de 11 a 14 años de edad) sobre el tipo de construcción del parque, razas de animales domésticos, especies de aves, el proceso del compostaje, el orbitrón, las plantas de la huerta, el proceso del gusano de seda; b) para el grado $9^{\circ}$ (estudiantes de 14 a 15 años de edad) sobre la clasificación del achiote, de las plantas, de las razas equinas, vacunas y caninas, y del búfalo; c) para los grados $10^{\circ}$ y $11^{\circ}$ (estudiantes de 15 a 18 años de edad), sobre los pesos en kilogramos de algunos animales, procesos físicos y químicos de obtención de esencia de las plantas aromáticas y su uso, el biodigestor y su utilidad, sistemas de bebederos de los diferentes animales, el aprovechamiento de aguas lluvias. Los estudiantes leyeron las guías con los profesores que realizaron aclaraciones y se acordó que los primeros llevasen las preguntas, libreta de anotaciones y lápices para escribir lo que consideraban pertinente para resolverlas.

Es necesario que el profesor tenga en cuenta que una visita a un museo o parque "no sustituye a un libro, ni a una conferencia, ni a una clase, ni a una 
revista, ni a un programa de TV, ni a una película... pero puede cambiar la actitud del ciudadano respecto a todo ello" (Wagensberg, 2007).

La intención didáctica de Panaca es utilizar escenarios naturales donde niños y adultos pueden ver, tocar, oler, alimentar, montar y disfrutar de todas aquellas actividades relacionadas con el sector agropecuario, para así "aprender divirtiéndose". Es la conjugación perfecta entre turismo, recreación, educación, cultura, comercialización, investigación y el uso de tecnologías apropiadas (relación entre ciencia, tecnología, sociedad y ambiente CTSA). También ayuda para la actividad de transversalidad curricular en educación ambiental y para resaltar las formas ecológicas de prevención, así como en el reconocimiento, estudio y la conservación integral de los suelos.

\section{Estrategias didácticas coinstruccionales y posinstruccionales en el desarrollo de los temas de ciencias naturales}

Para el desarrollo de las estrategias didácticas coinstruccionales se toman los temas afines que corresponden a las actitudes hacia el aprendizaje del ambiente con respeto a las plantas nativas, ornamentales y comestibles; cuidado de los animales y las especies nativas, conservación del agua, prevención de incendios y tratamiento de residuos y reciclajes. Para las actitudes hacia el aprendizaje de la actividad agraria se toman los temas del ciclo de la vida, los animales domésticos y los cultivos en relación con el ser humano. A continuación se presentan cada uno de ellos.

\section{Cuidado del ambiente}

El cuidado del ambiente es tema fundamental de la educación en ciencias naturales durante toda la educación reglada en los planes de estudios obligatorios en Colombia, aspecto que el Parque Temático de la Cultura Agropecuaria contiene en todas las estaciones de animales y plantas que se encuentran en él. Las guías didácticas para la visita al parque permiten establecer las relaciones entre las actividades humanas para lograr la superviven- cia a través de la alimentación pero con respeto por el ambiente.

- Cuidado de las plantas nativas, ornamentales y agrarias

Para el cuidado de las plantas nativas los estudiantes se motivaron participando en la siembra y el cuidado de las mismas, y el control orgánico de plagas. En cuanto a las plantas de la actividad agraria observaron y participaron en la siembra de semillas y realización del compostaje. También hicieron semilleros que luego se trasplantaron en la huerta escolar.

Como estrategia didáctica posinstruccional se redactaron los informes finales anexando fotos del proceso y se presentaron a los compañeros. Los cultivos obtenidos fueron de producción limpia, sin fumigantes químicos, y las plantas ornamentales fueron sanas, las hojas brillantes y la florescencia vistosa.

- Cuidado de los animales domésticos y las especies nativas

Las estrategias didácticas coinstruccionales de experiencias directas permitieron el conocimiento de los animales nativos de la región y de los animales domésticos tanto de compañía del ser humano como los de consumo alimenticio en la visita guiada a Panaca. Las estrategias didácticas de indagación y documentación permitieron comprender la importancia de estos animales en el ciclo de la vida, como también crear espíritu de sensibilidad, que se trasluce en comportamientos de respeto hacia las mascotas que conviven con los seres humanos y hacia la conservación de las especies silvestres en su hábitat natural.

El cuidado de los animales para el consumo, así como el hábitat, la alimentación, la salud y el proceso para la obtención de productos alimenticios con normas de higiene, fue un aspecto que influyó positivamente para que los estudiantes lograran adquirir actitudes positivas y que comprendieran este aspecto fundamental para la salud humana. 
El ambiente sociocultural influye indudablemente en los hábitos alimenticios, los cuales se cambian a medio y largo plazo.

\section{- Conservación del agua}

La información sobre la contaminación de las aguas con desechos inorgánicos contribuyó a que los estudiantes tomarán conciencia frente al cuidado del ambiente y, en este caso específico, el cuidado del agua potable. Las estrategias coinstruccionales utilizadas por el profesor durante del desarrollo del tema, además de la experiencia directa de la visita a Panaca, fueron documentales sobre la contaminación del agua y observación directa de contaminación con aceite, insecticidas y residuos químicos. Los estudiantes comprendieron la importancia de no consumir agua del grifo o sin hervir independientemente de la aprobación o no de sus padres y demás adultos, es decir, incorporaron a su vida un hábito que beneficia la salud.

\section{- Prevención de incendios}

Los estudiantes estaban interesados en el conocimiento de la prevención de incendios forestales, puesto que con frecuencia se observa en las noticias que estos se presentan en diferentes lugares del planeta afectando el ecosistema y arrasando con toda forma de vida, y produciendo pérdidas materiales y ecológicas irreparables. La visita a Panaca, y el desarrollo de temas en el ambiente formal del aula de clase permitieron que los estudiantes adquirieran conocimientos sobre la prevención y acción de incendios forestales y de la vivienda, conocimientos que podrán poner en práctica en su vida cotidiana urbana o rural y divulgar en su ambiente próximo.

\section{- Tratamiento de residuos y reciclaje}

La estrategia coinstruccional que se utilizó en la visita a Panaca fue la observación directa, puesto que allí existen recipientes para que los empleados y los visitantes depositen los residuos de acuerdo con su naturaleza, de tal forma que se separen. También observaron que se produce abonos y compostaje con los residuos orgánicos, y que los residuos no orgánicos, como los recipientes, se pueden reutilizar como semilleros, para empacar abonos y para bebederos de las aves.

El cambio de algunas actitudes negativas hacia el ambiente próximo de los estudiantes a positivas es difícil, como dicen Pozo y Gómez (1998): la forma de comportarse en clase y fuera de ella, sus valores, son elementos que cambiarán si hay un propósito educativo, deliberado e intencional [...] a través de la generación de necesidades, la motivación, el interés y la voluntad en los estudiantes hacia el aprendizaje de las ciencias naturales y el cuidado del ambiente (León et al., 2006). En la medida que los estudiante adquieren actitudes positivas hacia el reciclaje, cambian sus hábitos que se reflejan en comportamientos que en el futuro transmitirán a las generaciones venideras como parte integrante de la cultura. Lo más importante de la estrategia didáctica fue la experiencia directa de los estudiantes en la separación de residuos de papel, vidrio y plástico que entregaron directamente a las personas que reciclan en el sector aledaño al colegio.

\section{Actividad Agraria}

Los currículos pertinentemente culturales en sus planes de estudios incluyen en las áreas correspondientes los temas locales que fundamentan los conocimientos que se enmarcan en el orden global. A continuación se presentan las estrategias didácticas y los resultados cualitativos de la comparación de las actitudes de los estudiantes antes y después de la visita a Panaca, con respecto a la actividad agraria relacionada con el área de ciencias naturales.

\section{- Ciclo de la vida}

Se desarrollaron estrategias didácticas coinstruccionales de experiencias directas, analogías y comparaciones durante la visita planeada por el profesor a Panaca (ambiente no formal) y en el desarrollo de clases en el ambiente formal.

El ciclo de la vida es un tema que los estudiantes han visto desde la educación primaria, por tan- 
to, tienen conocimientos previos sobre el mismo; además, han estudiado los otros ciclos como el del agua; no hubo diferencias entre lo que creían era importante conocer sobre este tema y lo que conocieron. Sin embargo, algunos estudiantes indiferentes en ubicarse en el ciclo de la vida, cambiaron sus actitudes, demostrando de esta forma que se interesaron no solo por la visita al parque temático, sino también por las clases desarrolladas en el ambiente formal, donde intercambiaron información, analizaron y recrearon la visita con fotos y videos.

- Los animales domésticos y los cultivos en relación con el ser humano

Los estudiantes no tenían conocimiento de los componentes de los concentrados y la relación con la salud humana. En el ambiente formal los profesores utilizaron como estrategia didáctica coinstruccional la consulta por Internet sobre la composición de los alimentos producidos en laboratorios para los animales domésticos. Los estudiantes compartieron la información obtenida y analizaron los diferentes componentes de estos alimentos. Esto hizo que tomasen conciencia después de la visita a Panaca para decir que prefieren consumir los productos de animales criados y alimentados en el campo con alimentos propios que brinda la naturaleza como el pasto, el maíz, la yuca, el plátano, la miel, las verduras, el heno y la soya, entre otros.

En sus indagaciones encontraron que los concentrados para la alimentación animal contienen aditivos, aminoácidos, antibióticos, minerales, preservantes, secuestrante de micotoxinas, subproductos, coxidiostatos, desparasitantes, energéticos, fósforo sintético, granos, harina, levadura, sustitutos de leche, vitaminas y varios.

En cuanto al consumo de productos empacados, embutidos y enlatados de larga duración, los estudiantes consultaron sobre los aditivos que contienen. En los embutidos encontraron que además de carne tienen grasas, sal, azúcares, nitratos y nitritos, condimentos y especies. Los estudiantes analizaron la toxicidad de los aditivos y la cantidad de estos en el proceso de los alimentos. Estos aditivos deben ser sustancias perfectamente detectables y medibles, no deben interaccionar con el envase y deben carecer de toxicidad.

El estudio y análisis de los aditivos despertó interés en los estudiantes, les hizo generar necesidades de comprobar los componentes de los alimentos que consumen, interés que les permite reflexionar sobre su salud y elegir, en la medida que sea posible, alimentos procedentes de animales criados con alimentación natural, y procesados con normas de higiene y frescos. Lo mismo en cuanto a frutas y vegetales obtenidos de proceso de cultivos limpios y a los alimentos como jugos, leche, pan, atún, sardinas, empacados o enlatados de larga duración. Los estudiantes reflexionaron sobre su composición, aspecto que a mediano y largo plazo permitirá cambiar los hábitos alimenticios, puesto que el ambiente sociocultural influye en la alimentación de los grupos humanos. El conocimiento, la reflexión, el intercambio de información, la observación directa y la comprobación, estrategias didácticas que debe utilizar el profesor en ciencias naturales, permiten que los estudiantes mejoren su calidad de vida, que se reflejará en su entorno próximo.

En la visita a Panaca los estudiantes tuvieron la oportunidad de probar otros productos animales diferentes al ganado vacuno y porcino, como la leche de cabra, los quesos de cabra y de búfalo y los dulces de leche de cabra. También carne de otros animales como el búfalo, la cabra, los peces, el armadillo y el cuy, o huevos procedentes de los patos, los gansos, las codornices y las palomas, los cuales son ricos en proteínas. Aunque al hacer la comparación de los conocimientos previos con las respuestas posteriores las actitudes cambian positivamente, no todos están convencidos de poder incluir esos alimentos en su dieta alimenticia puesto que el ambiente familiar es más fuerte que las preferencias individuales de los estudiantes.

En cuanto al maltrato de los animales, después de la visita a Panaca los estudiantes comprendieron las condiciones adecuadas de higiene, aireación, alimentación, reproducción y salud en que deben ser tenidos los animales domésticos. Lo anterior implica que el cambio de actitudes positivas se debe a la obtención de conocimientos que no te- 
nían. Por ello, si habitan en el ambiente rural cambiarán la forma de cuidar los animales para el consumo humano, y si viven en la ciudad, respetarán los animales domésticos con buen trato, cuidado y alimentación adecuada, $\mathrm{y}$, además, vigilarán que otros lo hagan. Es decir, han creado conciencia moral frente al respeto por los animales domésticos y también frente a la importancia de que los animales silvestres deben protegerse para que permanezcan en su hábitat y no sean utilizados como mascotas.

\section{Diseño de postest de actitudes del aprendizaje de las ciencias}

Utilizadas las estrategias didácticas antes de la visita (preinstruccionales), durante la visita (coinstruccionales) y después de la visita (posinstruccionales) a Pananca, se requiere saber si los estudiantes despertaron el interés por las ciencias naturales, específicamente en los aspectos que conciernen a la actividad agraria propia de la cultura de la región donde viven.

Se diseñaron dos postest de actitudes: uno sobre la actividad agraria y otro sobre el ambiente, los cuales se aplican para conocer la generación de actitudes positivas hacia el aprendizaje de las ciencias naturales.

A continuación se presentan algunos ítems de los posttest de actitudes hacia el aprendizaje de las ciencias naturales en los aspectos del ambiente (tabla 2) y actividad agraria (tabla 1), los cuales se diseñan teniendo en cuenta los ítems de los pretest, pero se cambia el enunciado de tal forma que se permita determinar el cambio o no de las actitudes, es decir, se formulan los enunciados en forma de comportamientos.

Comparación de los resultados de los pretest y postest de actitudes del aprendizaje de las ciencias

Para la interpretación de los resultados se utilizó el paquete estadístico SPSS 12.0 para datos cualitativos, se presenta la comparación del pretest y del postest, con la comparación de las medias aritméticas, a través de la prueba t-student. En las tablas

\section{TABLA 1.}

\begin{tabular}{|l|l|l|l|l|l|l|}
\hline \multicolumn{7}{|l|}{ Valore las siguientes afirmaciones de acuerdo con la siguiente tabla de } \\
valores: 1 Estoy muy de acuerdo 2 Estoy de acuerdo 3 me es indiferente 4 \\
Estoy en desacuerdo 5 Estoy muy en desacuerdo \\
\hline $\begin{array}{l}\text { 2. Participo de la separación de las basuras en } \\
\text { recipientes diferentes. }\end{array}$ & 1 & 2 & 3 & 4 & 5 \\
\hline $\begin{array}{l}\text { 6. Participo de la búsqueda de controles orgáni- } \\
\text { cos de plagas para que se utilicen a cambio de } \\
\text { las fumigaciones con pesticidas. }\end{array}$ & 1 & 2 & 3 & 4 & 5 \\
\hline $\begin{array}{l}\text { 7. Doy información sobre la importancia de no } \\
\text { arrojar desechos orgánicos e inorgánicos a las } \\
\text { quebradas y ríos porque alteran las aguas. }\end{array}$ & 1 & 2 & 3 & 4 & 5 \\
\hline $\begin{array}{l}\text { 10. Realizo el compostaje con desechos orgánicos } \\
\text { de las mismas plantas. }\end{array}$ & 1 & 2 & 3 & 4 & 5 \\
\hline $\begin{array}{l}\text { 19. Indago sobre el procesamiento del café y los } \\
\text { desechos. }\end{array}$ & 1 & 2 & 3 & 4 & 5 \\
\hline
\end{tabular}

\section{TABLA 2.}

Valore las siguientes afirmaciones de acuerdo con la siguiente tabla de valores:

1 Estoy muy de acuerdo 2 Estoy de acuerdo 3 Me es indiferente

4 Estoy en desacuerdo 5 Estoy muy en desacuerdo

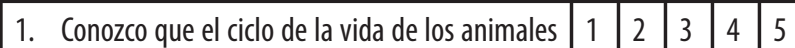
y vegetales tiene relación entre ellos y con el ser humano.

\begin{tabular}{|l|l|l|l|l|l|}
\hline 5. Indago sobre la forma de procesar los alimentos & 1 & 2 & 3 & 4 & 5
\end{tabular} provenientes de los animales y los vegetales para saber qué químicos utilizan y si afectan la salud de animales, vegetales y ser humano.

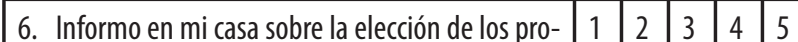
ductos alimenticios provenientes de los animales y los vegetales de consumo humano que debemos incluir en nuestra dieta.

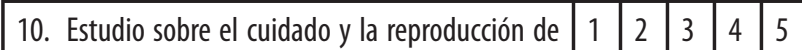
los animales domésticos para comprender importancia de ellos en la supervivencia de los seres humanos.

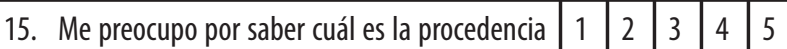
de los animales que se utilizan para el consumo en mi casa.

que se adjuntan aparecen los datos estadísticos relacionados para su comparación: el valor de las medias, el número de sujetos que participaron en el estudio $(\mathrm{N})$, la desviación típica y la probabilidad o significancia. En esta investigación de tipo 


\section{TABLA 3. Comparación de algunos ítems del pretest y el postest de actitudes hacia el ambiente}

\begin{tabular}{|l|c|c|c|c|}
\hline & \multicolumn{2}{|c|}{ Pretest } & \multicolumn{2}{c|}{ Postest } \\
& $\begin{array}{l}\text { Estoy convencido } \\
\text { que separar las ba- } \\
\text { suras es perder el } \\
\text { tiempo, porque el } \\
\text { carro de la basura } \\
\text { las revuelve }\end{array}$ & $\begin{array}{l}\text { le la se- } \\
\text { paración de basuras } \\
\text { en recipientes dife- } \\
\text { rentes }\end{array}$ \\
\hline & $\mathrm{N}$ & $\%$ & $\mathrm{~N}$ & $\%$ \\
\hline Estoy muy de acuerdo & 48 & 24,0 & 75 & 37,5 \\
\hline Estoy de acuerdo & 48 & 24,0 & 102 & 51,0 \\
\hline Me es indiferente & 24 & 12,0 & 21 & 10,5 \\
\hline Estoy en desacuerdo & 28 & 14,0 & 2 & 1,0 \\
\hline Estoy muy en desacuerdo & 51 & 25,5 & 0 & 0,0 \\
\hline No contestó & 1 &, 5 & 0 & 0,0 \\
\hline Total & 200 & 100,0 & 200 & 100,0 \\
\hline
\end{tabular}

descriptivo se toma como nivel de significancia a $=0,05$. El valor de significancia (sig, bilateral) es el valor de probabilidad o "significancia" de los resultados. Si es menor a $\alpha=0,05$ existen diferencias significativas entre los dos ítems que se comparan, para concluir el cambio o no de las actitudes de los estudiantes con respecto al ambiente o a las actividades agrarias de la región.

Es importante aclarar que algunos ítems del pretest se redactaron en forma negativa. Para poder realizar la comparación entre este instrumento y el postest fue necesario invertir los resultados de los ítems negativos, por eso en las tablas se encontrará entre paréntesis invertido.

En los resultados de la prueba $\mathrm{T}$ (tabla 4) el nivel de significancia es inferior a $a=0,05(0,00<$ $0,05)$, por tanto, existen diferencias significativas entre las respuestas del pretest y el postest. Lo que implica que la actitud hacia este aspecto de la separación de basuras cambió positivamente en los estudiantes. Más o menos la mitad de la muestra de estudiantes (tabla 3 ) consideraban que no se debería separar las basuras porque el camión de recolección las introduce todas sin distinciones de los residuos. Después de la visita a Panaca los estu-
TABLA 4. Prueba T. Comparación de medias Estadísticos de muestras y pruebas relacionadas

\begin{tabular}{|c|c|c|c|c|}
\hline & $\frac{\text { 음 }}{\frac{0}{2}}$ & $z$ & 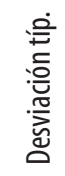 & 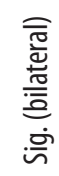 \\
\hline $\begin{array}{l}\text { Estoy convencido de que separar } \\
\text { las basuras es perder el tiempo } \\
\text { porque el carro de la basura las } \\
\text { revuelve (invertido). }\end{array}$ & 3,10 & 200 & 1,54 & 0,00 \\
\hline $\begin{array}{l}\text { Participo de la separación de ba- } \\
\text { suras en recipientes diferentes. }\end{array}$ & 1,75 & 200 & 0,68 & \\
\hline
\end{tabular}

diantes comprendieron la importancia de separarlas por la experiencia que se vive en el parque, y en el postest dicen (tabla 3 ) que están muy de acuerdo $(37,5 \%)$ y están de acuerdo (51\%) en participar de la separación de la basuras. Los residuos de papel, cartón, empaques plásticos y empaques de vidrio, si los introducen en bolsas aparte, no se van al camión de recolección de basuras porque los recogen personas que se dedican al reciclaje.

En los resultados de la prueba $\mathrm{T}$ (tabla 6) el nivel de significancia es inferior a $\alpha=0,05,(0,01>0,05)$, lo cual implica que existen diferencias significativas

\begin{tabular}{|c|c|c|c|c|}
\hline \multicolumn{5}{|l|}{ TABLA 5.} \\
\hline & \multicolumn{2}{|c|}{$\begin{array}{l}\text { Pretest } \\
\text { Creo que es im- } \\
\text { portante indagar } \\
\text { sobre los contro- } \\
\text { les orgánicos de } \\
\text { plagas para que } \\
\text { reemplacen las } \\
\text { fumigaciones con } \\
\text { pesticidas }\end{array}$} & \multicolumn{2}{|c|}{$\begin{array}{l}\text { Postest } \\
\text { Participo de la } \\
\text { búsqueda de con- } \\
\text { troles orgánicos de } \\
\text { plagas para que se } \\
\text { utilicen a cambio } \\
\text { de las fumigacio- } \\
\text { nes con pesticidas }\end{array}$} \\
\hline & $\mathrm{N}$ & $\%$ & $\mathrm{~N}$ & $\%$ \\
\hline Estoy muy de acuerdo & 68 & 34,0 & 54 & 27,0 \\
\hline Estoy de acuerdo & 59 & 29,5 & 89 & 44,5 \\
\hline Me es indiferente & 34 & 17,0 & 36 & 18,0 \\
\hline Estoy en desacuerdo & 12 & 6,0 & 16 & 8,0 \\
\hline Estoy muy en desacuerdo & 21 & 10,5 & 5 & 2,5 \\
\hline No contestó & 6 & 3,0 & 0 & 0,0 \\
\hline Total & 200 & 100,0 & 200 & 100,0 \\
\hline
\end{tabular}




\section{TABLA 6. Prueba T. Comparación de medias Estadísticos de muestras y pruebas relacionadas}

\begin{tabular}{|c|c|c|c|c|}
\hline & $\stackrel{\frac{\pi}{0}}{\frac{\pi}{0}}$ & $z$ & 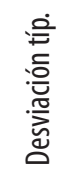 & 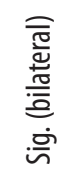 \\
\hline $\begin{array}{l}\text { Creo que es importante indagar } \\
\text { sobre los controles orgánicos de } \\
\text { plagas para que reemplacen las } \\
\text { fumigaciones con pesticidas }\end{array}$ & 2,39 & 200 & 1,43 & \multirow[t]{2}{*}{0,01} \\
\hline $\begin{array}{l}\text { Participo de la búsqueda de con- } \\
\text { troles orgánicos de plagas para que } \\
\text { se utilicen a cambio de las fumiga- } \\
\text { ciones con pesticidas }\end{array}$ & 2,15 & 200 & 0,99 & \\
\hline
\end{tabular}

entre las respuestas del pretest y el postest. Es decir, que la actitud por indagar sobre los controles orgánicos de plagas (tabla 6: está muy de acuerdo $34 \%$ y estoy de acuerdo 29,5\%) se convirtió en comportamiento declarado (tabla 9: está muy de acuerdo $27 \%$ y estoy de acuerdo $44,5 \%$ ), pero los demás no se interesaron en este aspecto, bien sea porque en sus familias no tienen contacto con la actividad agraria, o simplemente no les interesa o son indiferentes (tabla 5: pretest $17 \%$, postest $18 \%$ ). Para

\section{TABLA 7}

\begin{tabular}{|c|c|c|c|c|c|}
\hline \multirow{2}{*}{\multicolumn{2}{|c|}{ 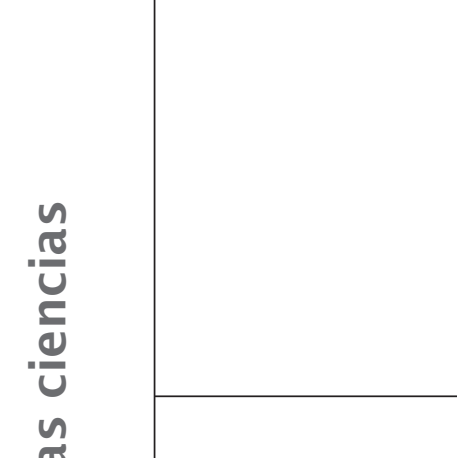 }} & \multicolumn{2}{|c|}{$\begin{array}{l}\text { Pretest } \\
\text { Estoy seguro que } \\
\text { arrojar desechos in- } \\
\text { orgánicos a las que- } \\
\text { bradas y los ríos no } \\
\text { los alteran porque } \\
\text { ellos no se descom- } \\
\text { ponen }\end{array}$} & \multicolumn{2}{|c|}{\begin{tabular}{l}
\multicolumn{1}{c}{ Postest } \\
Doy información \\
sobre la importan- \\
cia de no arrojar \\
desechos orgánicos \\
e inorgánicos a las \\
quebradas y ríos \\
porque alteran las \\
aguas
\end{tabular}} \\
\hline & & N & $\%$ & $\mathrm{~N}$ & $\%$ \\
\hline \multirow{6}{*}{ 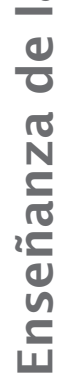 } & Estoy muy de acuerdo & 24 & 12,0 & 99 & 49,5 \\
\hline & Estoy de acuerdo & 15 & 7,5 & 75 & 37,5 \\
\hline & Me es indiferente & 25 & 12,5 & 11 & 5,5 \\
\hline & Estoy en desacuerdo & 40 & 20,0 & 13 & 6,5 \\
\hline & Estoy muy en desacuerdo & 96 & 48,0 & 2 & 1,0 \\
\hline & Total & 200 & 100,0 & 200 & 100,0 \\
\hline
\end{tabular}

que los profesores logren cambiar las actitudes de los estudiantes a medio y largo plazo deberán realizar trabajos de campo directamente en la huerta escolar o en otros escenarios, que permitan poner en práctica la utilización de los dos controles de plagas, químicos y orgánicos, y comparar el valor nutritivo de los productos en el laboratorio.

En los resultados de la prueba $\mathrm{T}$ (tabla 8) el nivel de significancia es inferior a $\alpha=0,05$, es decir, existen diferencias significativas entre las respuestas del pretest y el postest (tabla 7). La actitud de no arrojar desechos inorgánicos a las quebradas y ríos mejoró positivamente en los estudiantes, porque participan de la divulgación de la importancia de los cuidados de las aguas. Implica que los conocimientos adquiridos sobre el cuidado del agua y el tratamiento de los desechos en la visita a Panaca impactó en los estudiantes. La ampliación de estos temas en el ambiente formal favoreció que los estudiantes se integraran a grupos para el cuidado del ambiente. Existe un grupo de estudiantes que siguen indiferentes (tabla 7) y que no tienen interés por el tema. El profesor puede integrarlos a grupos de cuidado de las quebradas para que observen directamente y ayuden a recoger los desechos que se encuentran en ellas.

En los resultados de la prueba $\mathrm{T}$ (tabla 10) el nivel de significancia es inferior a $\alpha=0,05$, por tanto, se

TABLA 8. Prueba T. Comparación de medias Estadísticos de muestras y pruebas relacionadas

\begin{tabular}{|c|c|c|c|c|}
\hline & $\frac{\sqrt[\pi]{\mathrm{g}}}{\sum^{\frac{0}{L}}}$ & $z$ & 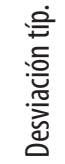 & 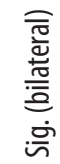 \\
\hline $\begin{array}{l}\text { Estoy seguro que arrojar dese- } \\
\text { chos inorgánicos a las quebra- } \\
\text { das y ríos no los alteran porque } \\
\text { ellos no se descomponen (in- } \\
\text { vertido) }\end{array}$ & 2,23 & 200 & 1,44 & \multirow[t]{2}{*}{0,00} \\
\hline $\begin{array}{l}\text { Doy información sobre la im- } \\
\text { portancia de no arrojar dese- } \\
\text { chos orgánicos e inorgánicos } \\
\text { a las quebradas y ríos porque } \\
\text { alteran las aguas }\end{array}$ & 1,58 & 200 & 0,75 & \\
\hline
\end{tabular}

REVISTA CIENTÍFICA / ENERO -DICIEMBRE DE 2009 / No. 11 / BOGOTÁ, D.C. 


\section{TABLA 9.}

\begin{tabular}{|c|c|c|c|c|}
\hline & \multicolumn{2}{|c|}{$\begin{array}{l}\text { Pretest } \\
\text { Creo que el compos- } \\
\text { taje se realiza con de- } \\
\text { sechos orgánicos de } \\
\text { la misma producción } \\
\text { de las plantas }\end{array}$} & \multicolumn{2}{|c|}{$\begin{array}{l}\quad \text { Postest } \\
\text { Realizo el compostaje } \\
\text { con desechos orgáni- } \\
\text { cos de las mismas } \\
\text { plantas }\end{array}$} \\
\hline & N & $\%$ & $\mathrm{~N}$ & $\%$ \\
\hline Estoy muy de acuerdo & 43 & 21,5 & 48 & 24,0 \\
\hline Estoy de acuerdo & 46 & 23,0 & 115 & 57,5 \\
\hline Me es indiferente & 58 & 29,0 & 21 & 10,5 \\
\hline Estoy en desacuerdo & 23 & 11,5 & 11 & 5,5 \\
\hline Estoy muy en desacuerdo & 27 & 13,5 & 2 & 1,0 \\
\hline No contestó & 3 & 1,5 & 3 & 1,5 \\
\hline Total & 200 & 100,0 & 200 & 100,0 \\
\hline
\end{tabular}

TABLA 10. Prueba T. Comparación de medias Estadísticos de muestras y pruebas relacionadas

\begin{tabular}{|c|c|c|c|c|}
\hline & 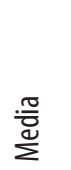 & $z$ & 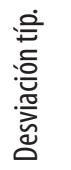 & 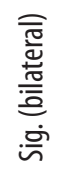 \\
\hline $\begin{array}{l}\text { Creo que el compostaje se } \\
\text { realiza con desechos orgánicos } \\
\text { de la misma producción de las } \\
\text { plantas }\end{array}$ & 2,77 & 200 & 1,36 & \multirow[t]{2}{*}{0,00} \\
\hline $\begin{array}{l}\text { Realizo el compostaje con } \\
\text { desechos orgánicos de las } \\
\text { mismas plantas }\end{array}$ & 2,07 & 200 & 0,95 & \\
\hline
\end{tabular}

observa que existen diferencias significativas entre las respuestas del pretest y el postest. La actitud hacia la realización del compostaje cambió positivamente en los estudiantes, los cuales en Panaca adquirieron conocimientos sobre la forma de realizarlo y pusieron en práctica esos conocimientos. Algunos estudiantes pertenecen al sector rural y esos conocimientos los extienden a su familia. Otros también participan de la obtención de abono orgánico para las plantas del colegio, la casa y de la huerta escolar o familiar. La indiferencia bajó de 29 a $10 \%$, y quienes no se interesaban por este aspecto del compostaje también disminuyeron (tabla 9) de 11,5 a $5,5 \%$ y de 13,5 a $1,5 \%$. El profesor de ciencias debe utilizar una estrategia didáctica en contexto no formal en el colegio o fuera de él, que

\section{TABLA 11.}

\begin{tabular}{|l|r|r|r|r|}
\hline & \multicolumn{2}{c|}{$\begin{array}{c}\text { Pretest } \\
\text { Considero impor- } \\
\text { tante saber cómo } \\
\text { se procesa el café y } \\
\text { qué se hace con los } \\
\text { desechos }\end{array}$} & \multicolumn{2}{l|}{$\begin{array}{l}\text { Postest } \\
\text { Indago sobre el pro- } \\
\text { y los desechos }\end{array}$} \\
\hline & $\mathrm{N}$ & \multicolumn{1}{|c|}{$\%$} & $\mathrm{~N}$ & \multicolumn{1}{c|}{$\%$} \\
\hline Estoy muy de acuerdo & 92 & 46,0 & 105 & 52,5 \\
\hline Estoy de acuerdo & 63 & 31,5 & 67 & 33,5 \\
\hline Me es indiferente & 29 & 14,5 & 18 & 9,0 \\
\hline Estoy en desacuerdo & 8 & 4,0 & 7 & 3,5 \\
\hline Estoy muy en desacuerdo & 5 & 2,5 & 3 & 1,5 \\
\hline No contestó & 3 & 1,5 & 0 & 0,0 \\
\hline Total & $\mathbf{2 0 0}$ & $\mathbf{1 0 0 , 0}$ & $\mathbf{2 0 0}$ & $\mathbf{1 0 0 , 0}$ \\
\hline
\end{tabular}

TABLA 12. Prueba T. Comparación de medias Estadísticos de muestras y pruebas relacionadas

\begin{tabular}{|c|c|c|c|c|}
\hline & $\sum^{\frac{\pi}{0}}$ & $z$ & 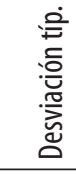 & 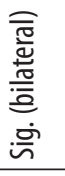 \\
\hline $\begin{array}{l}\text { Considero importante saber cómo } \\
\text { se procesa el café y qué se hace con } \\
\text { los desechos }\end{array}$ & 1,90 & 200 & 1,11 & \multirow[t]{2}{*}{0,03} \\
\hline $\begin{array}{l}\text { Indago sobre el procesamiento del } \\
\text { café y los desechos }\end{array}$ & 1,68 & 200 & 0,89 & \\
\hline
\end{tabular}

les permita a los estudiantes realizar el compostaje, observar el proceso y comparar el crecimiento de las plantas a las que se les agrega el compostaje con plantas que no se abonan.

En los resultados de la prueba $\mathrm{T}$ (tabla 12) el nivel de significancia es inferior a $\alpha=0,05,(0,03<$ $0,05)$, lo que implica diferencias significativas entre las respuestas del pretest y el postest. No todos los estudiantes estaban interesados en conocer el procesamiento del café y lo que se hace con los desechos. Después de la visita a Panaca, donde ampliamente conocieron y participaron del procesamiento del café, en las clases en el contexto formal los estudiantes se motivaron para conocer sobre este tema y la utilización de sus desechos orgánicos. Con respecto a la indiferencia (tabla 11) sobre el tema del café pasó de $14,5 \%$ en el pretest, a $9 \%$ en 


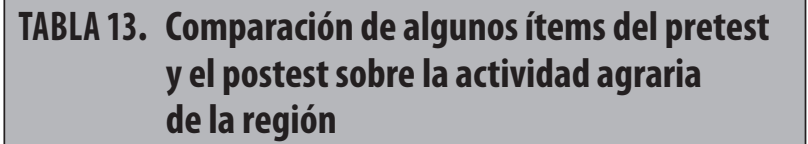

\begin{tabular}{|l|c|c|c|c|}
\hline & $\begin{array}{c}\text { Pretest } \\
\text { Estoy convencido que } \\
\text { si los animales do- } \\
\text { mésticos se alimentan } \\
\text { con comida industrial } \\
\text { (concentrados) crece- } \\
\text { rán más rápido y esto } \\
\text { no afectan la salud } \\
\text { humana }\end{array}$ & $\begin{array}{l}|c| \\
\text { Me gusta elegir para } \\
\text { la alimentación car- } \\
\text { nes de animales cria- } \\
\text { dos con alimentación } \\
\text { natural }\end{array}$ \\
\cline { 2 - 5 } & $\mathbf{N}$ & $\%$ & N & $\%$ \\
\hline Estoy muy de acuerdo & 51 & 25,5 & 69 & 34,5 \\
\hline Estoy de acuerdo & 44 & 22,0 & 76 & 38,0 \\
\hline Me es indiferente & 47 & 23,5 & 34 & 17,0 \\
\hline Estoy en desacuerdo & 34 & 17,0 & 10 & 5,0 \\
\hline Estoy muy en desacuerdo & 22 & 11,0 & 11 & 5,5 \\
\hline No contestó & 2 & 1,0 & 0 & 0 \\
\hline Total & $\mathbf{2 0 0}$ & $\mathbf{1 0 0 , 0}$ & $\mathbf{2 0 0}$ & $\mathbf{1 0 0}$ \\
\hline
\end{tabular}

el postest, y a quienes no les interesa también bajó de 4 a 3,5\% (en desacuerdo), y de 2,5\% bajó a 1,5\% (muy en desacuerdo). Siendo el café el principal renglón de la economía de la región, es importante que los ciudadanos inmersos en la cultura del café conozcan todo cuanto tiene que ver con el tema, y principalmente sobre la reutilización de los desechos para disminuir la contaminación. El profesor de ciencias deben incluir en el temario el café y todo su proceso como estudio dentro del currículo

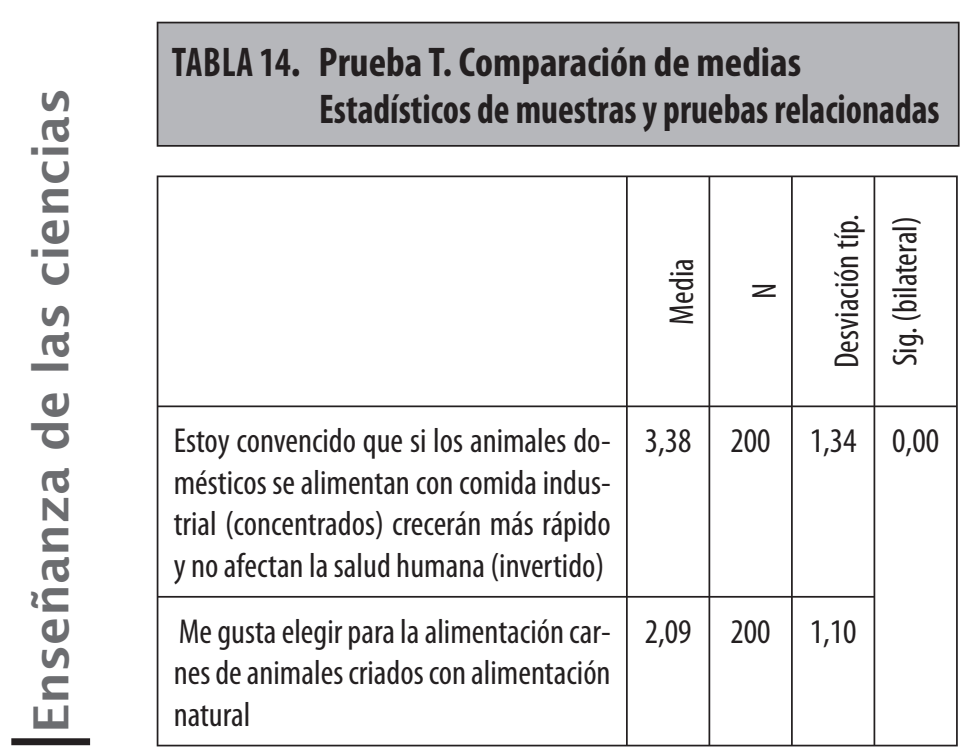

90 pertinentemente cultural, teniendo en cuenta que de alguna forma los estudiantes están relacionados con el café bien sea directa o indirectamente. El proceso del café se encuentra en inmediaciones del ámbito escolar, por tanto, se pueden desarrollar clases en contextos no formales en los terrenos mismos donde se cultiva y se procesa el café.

En los resultados de la prueba $\mathrm{T}$ (tabla 14) el nivel de significancia es inferior a $\alpha=0,05$, es decir, existen diferencias significativas entre las respuestas del pretest y el postest. La mayoría de los estudiantes creían que el consumo de los concentrados por parte de los animales no afecta la salud humana. Después de la visita a Panaca y del desarrollo de clases en contexto formal, los estudiantes dicen que prefieren elegir para el consumo carnes de animales criados con alimentación natural. La indiferencia sobre la alimentación de los animales de consumo humano era de 23,5\% y bajó al 17\% (tabla 13), sin embargo, otros no están interesados en el tema. El profesor debe diseñar experiencias didácticas que permitan a los estudiantes comprender el tema, como visitas a las empresas que procesan alimentos de procedencia animal para convertirlos en embutidos como salchicha, jamón, salchichón, etcétera, y escribir los componentes químicos que se agregan para su conservación. Luego consultar tales compuestos químicos y las consecuencias para la salud humana. De esta forma se adquieren conocimientos y surgen necesidades de cuidado de la salud.

En los resultados de la prueba $\mathrm{T}$ (tabla 16) el nivel de significancia es inferior a $\alpha=0,05$ es decir, existen diferencias significativas entre las respuestas del pretest y el postest. El $60 \%$ de los estudiantes dice estar muy de acuerdo y de acuerdo (tabla 15) en que saber sobre la forma de procesar alimentos animales y vegetales les ayuda a obtener buenas calificaciones. En el postest el 79\% está muy de acuerdo y de acuerdo en indagar para saber si las sustancias químicas que utilizan para procesar alimentos vegetales y animales afectan su salud. Los estudiantes han adoptado comportamientos positivos después de la visita a Panaca y de las clases; sin embargo, se mantiene el $17 \%$ de indiferencia (tabla 15) frente a este tema, y disminuyeron los que estaban en desacuerdo y muy en desacuerdo. 


\section{TABLA 15.}

\begin{tabular}{|c|c|c|c|c|}
\hline & \multicolumn{2}{|c|}{$\begin{array}{l}\text { Creo que conocer } \\
\text { sobre la forma de } \\
\text { procesar los ali- } \\
\text { mentos provenien- } \\
\text { tes de los animales } \\
\text { y vegetales influye } \\
\text { en que obtenga } \\
\text { buenas califica- } \\
\text { ciones en ciencias } \\
\text { naturales }\end{array}$} & \multicolumn{2}{|c|}{$\begin{array}{l}\text { Indago sobre la } \\
\text { forma de procesar } \\
\text { los alimentos pro- } \\
\text { venientes de los } \\
\text { animales y los ve- } \\
\text { getales para saber } \\
\text { qué químicos utili- } \\
\text { zan y si afectan la } \\
\text { salud de animales, } \\
\text { vegetales y ser hu- } \\
\text { mano }\end{array}$} \\
\hline & $\mathbf{N}$ & $\%$ & $\mathbf{N}$ & $\%$ \\
\hline Estoy muy de acuerdo & 60 & 30,0 & 66 & 33,0 \\
\hline Estoy de acuerdo & 60 & 30,0 & 92 & 46,0 \\
\hline Me es indiferente & 36 & 18,0 & 34 & 17,0 \\
\hline Estoy en desacuerdo & 35 & 17,5 & 6 & 3,0 \\
\hline Estoy muy en desacuerdo & 9 & 4,5 & 2 & 1,0 \\
\hline Total & 200 & 100,0 & 200 & 100,0 \\
\hline
\end{tabular}

El profesor debe buscar otras estrategias didácticas como visitas a empresas procesadoras de alimentos para interesarlos en este tema.

En los resultados de la prueba $\mathrm{T}$ (tabla 18) el nivel de significancia es inferior a $a=0,05$, por tanto, existen diferencias significativas entre las respuestas

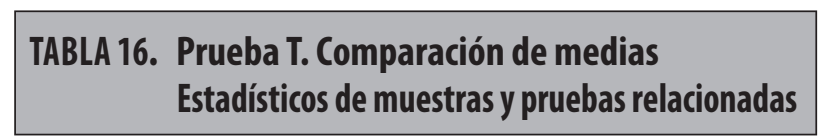

\begin{tabular}{|c|c|c|c|c|}
\hline & $\stackrel{\text { 을 }}{\sum^{\frac{d}{2}}}$ & $z$ & 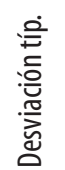 & 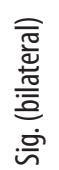 \\
\hline $\begin{array}{l}\text { Creo que conocer sobre la forma de } \\
\text { procesar los alimentos provenientes } \\
\text { de los animales y vegetales, influye } \\
\text { en que obtenga buenas calificaciones } \\
\text { en ciencias naturales }\end{array}$ & 2,37 & 200 & 1,21 & \multirow[t]{2}{*}{0,00} \\
\hline $\begin{array}{l}\text { Indago sobre la forma de procesar los } \\
\text { alimentos provenientes de los ani- } \\
\text { males y los vegetales, para saber qué } \\
\text { químicos utilizan y si afectan la salud } \\
\text { de animales, vegetales y ser humano. }\end{array}$ & 1,93 & 200 & 0,84 & \\
\hline
\end{tabular}

REVISTA CIENTÍFICA / ENERO -DICIEMBRE DE 2009 / No. 11 / BOGOTÁ, D.C.
TABLA 17.

\begin{tabular}{|c|c|c|c|c|}
\hline & \multicolumn{2}{|c|}{\begin{tabular}{l}
\multicolumn{1}{c}{ Pretest } \\
Pediré información \\
a los profesores so- \\
bre la elección de los \\
productos alimen- \\
ticios provenientes \\
de los animales y los \\
vegetales de consu- \\
mo humano
\end{tabular}} & \multicolumn{2}{|c|}{\begin{tabular}{l}
\multicolumn{2}{c}{ postest } \\
Informo en mi casa \\
sobre la elección \\
de los productos \\
alimenticios pro- \\
venientes de los \\
animales y los \\
vegetales de con- \\
sumo humano que \\
debemos incluir en \\
nuestra dieta
\end{tabular}} \\
\hline & $\mathbf{N}$ & $\%$ & $\mathbf{N}$ & $\%$ \\
\hline Estoy muy de acuerdo & 68 & 34,0 & 67 & 33,5 \\
\hline Estoy de acuerdo & 69 & 34,5 & 107 & 53,5 \\
\hline Me es indiferente & 35 & 17,5 & 18 & 9,0 \\
\hline Estoy en desacuerdo & 17 & 8,5 & 3 & 1,5 \\
\hline $\begin{array}{l}\text { Estoy muy en } \\
\text { desacuerdo }\end{array}$ & 11 & 5,5 & 5 & 2,5 \\
\hline Total & 200 & 100,0 & 200 & 100,0 \\
\hline
\end{tabular}

del pretest y el postest. El 68,5\% de los estudiantes dice en el pretest (tabla 17) estar muy de acuerdo y de acuerdo en pedir información a los profesores sobre la elección de los productos alimenticios animales y vegetales para su consumo. Después de la visita a Panaca, donde observaron y vivenciaron el adecuado proceso de los productos animales y

TABLA 18. Prueba T. Comparación de medias Estadísticos de muestras y pruebas relacionadas

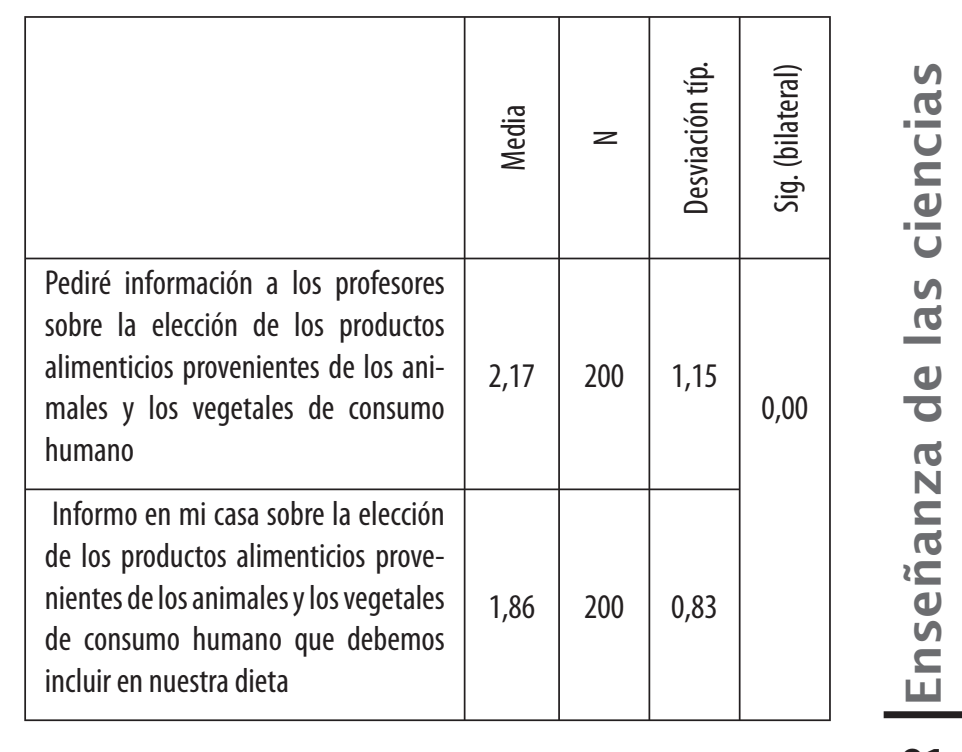


vegetales para el consumo humano, en el postest los estudiantes presentan comportamientos positivos puesto que el $87 \%$ dicen que informan en sus casas la adecuada elección de estos productos para incluirlos en la dieta cotidiana (muy de acuerdo y de acuerdo). La indiferencia bajó, lo mismo que quienes dicen estar en desacuerdo y muy en desacuerdo. La educación para el cambio de actitudes es fructífera si se crean necesidades y se brindan las experiencias y los conocimientos que permiten que ellas se transformen, observándose en los comportamientos.

En los resultados de la prueba $\mathrm{T}$ (tabla 20) el nivel de significancia es superior a $\mathrm{a}=0,05(0,18>0,05)$, por tanto, no existen diferencias significativas entre las respuestas del pretest y el postest. En el pretest los estudiantes presentan interés positivo en las actitudes hacia el estudio del cuidado y la reproducción de los animales domésticos para la supervivencia de los seres humanos. Aunque un buen grupo tenía actitudes positivas hacia este aspecto (tabla 19), se sumaron otros logrando comportamientos positivos hacia este tema. La participación en las actividades agrarias en Panaca motivó a los estudiantes a indagar y conocer más sobre el tema. La indiferencia, que en pretest era del $15 \%$, en el postest bajó al 7\% (tabla 19), y unos pocos estudiantes dicen no estudiar la vida de los animales domésticos. El profesor debe buscar otras estrategias didácticas que les permitan a los estudiantes interesarse por el estudio de estos animales tan importantes para la supervivencia de ellos mismos y del ecosistema.

En los resultados de la prueba T (tabla 22) el nivel de significancia es inferior a $a=0,05(0,00<0,05)$, lo que permite afirmar que existen diferencias significativas entre las respuestas del pretest y el postest. Los estudiantes en el pretest (tabla 21) presentaron conocimiento sobre el tema de la influencia de la salud de los animales para el consumo en la salud humana (estoy en desacuerdo, $14,5 \%$ y estoy muy en desacuerdo, 26\%). En el postest los estudiantes dicen que se preocupan por saber la procedencia de los animales que consumen (muy de acuerdo, $47 \%$ y de acuerdo, $40 \%$ ), puesto que obtuvieron conocimientos de que su salud afecta la salud hu-

\section{TABLA 19.}

\begin{tabular}{|c|c|c|c|c|}
\hline & \multicolumn{2}{|c|}{$\begin{array}{l}\text { Pretest } \\
\text { Creo que conocer } \\
\text { sobre el cuidado y la } \\
\text { reproducción de los } \\
\text { animales domésticos } \\
\text { me permitirá com- } \\
\text { prender la impor- } \\
\text { tancia de ellos en la } \\
\text { supervivencia de los } \\
\text { seres humanos }\end{array}$} & \multicolumn{2}{|c|}{$\begin{array}{l}\text { Postest } \\
\text { Estudio sobre el cui- } \\
\text { dado y la reproduc- } \\
\text { ción de los animales } \\
\text { domésticos para } \\
\text { comprender la im- } \\
\text { portancia de ellos en } \\
\text { la supervivencia de } \\
\text { los seres humanos }\end{array}$} \\
\hline & N & $\%$ & N & $\%$ \\
\hline Estoy muy de acuerdo & 80 & 40,0 & 85 & 42,5 \\
\hline Estoy de acuerdo & 69 & 34,5 & 83 & 41,5 \\
\hline Me es indiferente & 30 & 15,0 & 14 & 7,0 \\
\hline Estoy en desacuerdo & 11 & 5,5 & 12 & 6,0 \\
\hline $\begin{array}{l}\text { Estoy muy en } \\
\text { desacuerdo }\end{array}$ & 10 & 5,0 & 4 & 2,0 \\
\hline No contestó & 0 & 0,0 & 2 & 1,0 \\
\hline Total & 200 & 100,0 & 200 & 100,0 \\
\hline
\end{tabular}

TABLA 20. Prueba T. Comparación de medias Estadísticos de muestras y pruebas relacionadas

\begin{tabular}{|c|c|c|c|c|}
\hline & $\stackrel{\text { 음 }}{\stackrel{0}{2}}$ & $z$ & 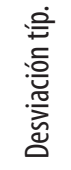 & 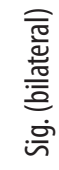 \\
\hline $\begin{array}{l}\text { Creo que conocer sobre } \\
\text { el cuidado y la repro- } \\
\text { ducción de los animales } \\
\text { domésticos me per- } \\
\text { mitirá comprender la } \\
\text { importancia de ellos en } \\
\text { la supervivencia de los } \\
\text { seres humanos }\end{array}$ & 2,01 & 200 & 1,11 & \\
\hline $\begin{array}{l}\text { Estudio sobre el cuida- } \\
\text { do y la reproducción de } \\
\text { los animales domésti- } \\
\text { cos para comprender la } \\
\text { importancia de ellos en } \\
\text { la supervivencia se los } \\
\text { seres humanos }\end{array}$ & 1,87 & 200 & 1,03 & 0,18 \\
\hline
\end{tabular}

REVISTA CIENTÍFICA / ENERO -DICIEMBRE DE 2009 / No. 11 / BOGOTÁ, D.C. 


\section{TABLA 21.}

\begin{tabular}{|c|c|c|c|c|}
\hline & \multicolumn{2}{|c|}{$\begin{array}{l}\text { Pretest } \\
\text { Las enfermedades de } \\
\text { los animales que se } \\
\text { utilizan para el con- } \\
\text { sumo no afectan la } \\
\text { salud humana }\end{array}$} & \multicolumn{2}{|c|}{$\begin{array}{l}\text { Postest } \\
\text { Me preocupo por } \\
\text { saber cuál es la pro- } \\
\text { cedencia de los ani- } \\
\text { males que se utilizan } \\
\text { para el consumo en } \\
\text { mi casa }\end{array}$} \\
\hline & $\mathbf{N}$ & $\%$ & $\mathbf{N}$ & $\%$ \\
\hline Estoy muy de acuerdo & 36 & 18,0 & 94 & 47,0 \\
\hline Estoy de acuerdo & 32 & 16,0 & 80 & 40,0 \\
\hline Me es indiferente & 46 & 23,0 & 18 & 9,0 \\
\hline Estoy en desacuerdo & 29 & 14,5 & 5 & 2,5 \\
\hline $\begin{array}{l}\text { Estoy muy } \\
\text { en desacuerdo }\end{array}$ & 52 & 26,0 & 2 & 1,0 \\
\hline No contestó & 5 & 2,5 & 1 &, 5 \\
\hline Total & 200 & 100,0 & 200 & 100,0 \\
\hline
\end{tabular}

mana. En la visita a Panaca pudieron evidenciar, a partir de la cercanía a los instructores y cuidadores de los animales domésticos, la información sobre la salud de los animales y sus influencias en los demás seres vivos que los consumen. Este aspecto se reforzó en el contexto formal en el aula de clase. Sin embargo, algunos estudiantes son indiferentes al respecto, hecho que se puede superar con información adicional a través de videos, visitas al ma-

\section{TABLA 22. Prueba T. Comparación de medias Estadísticos de muestras y pruebas relacionadas}

\begin{tabular}{|c|c|c|c|c|}
\hline & $\frac{.0}{\overline{0}}$ & $z$ & 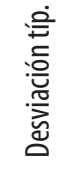 & 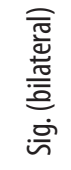 \\
\hline $\begin{array}{l}\text { Las enfermedades de los ani- } \\
\text { males que se utilizan para el } \\
\text { consumo no afectan la salud } \\
\text { humana (invertido) }\end{array}$ & 2,96 & 200 & 1,52 & \multirow[t]{2}{*}{0,00} \\
\hline $\begin{array}{l}\text { Me preocupo por saber cuál } \\
\text { es la procedencia de los } \\
\text { animales que se utilizan para } \\
\text { el consumo en mi casa }\end{array}$ & 1,72 & 200 & 0,87 & \\
\hline
\end{tabular}

\section{TABLA 23.}

\begin{tabular}{|l|c|c|c|c|}
\hline & \multicolumn{2}{|c|}{$\begin{array}{c}\text { Pretest } \\
\text { Creo que conocer s0- } \\
\text { bre la forma de pro- } \\
\text { cesar los productos } \\
\text { animales y vegetales } \\
\text { me permitirá elegir } \\
\text { cuáles consumo }\end{array}$} & $\begin{array}{c}\text { Prefiero los derivados } \\
\text { de animales y vegeta- } \\
\text { les no procesados }\end{array}$ \\
\hline Estoy muy de acuerdo & 72 & 36,0 & 27 & 13,5 \\
\hline Estoy de acuerdo & 60 & 30,0 & 45 & 22,5 \\
\hline Me es indiferente & 47 & 23,5 & 46 & 23,0 \\
\hline Estoy en desacuerdo & 9 & 4,5 & 32 & 16,0 \\
\hline Estoy muy & 10 & 5,0 & 45 & 22,5 \\
en desacuerdo & 2 & 1,0 & 5 & 2,5 \\
\hline No contestó & $\mathbf{2 0 0}$ & $\mathbf{1 0 0 , 0}$ & $\mathbf{2 0 0}$ & $\mathbf{1 0 0 , 0}$ \\
\hline Total & & & & \\
\hline
\end{tabular}

tadero municipal, y que podría influir en el cambio de actitudes positivas hacia indagar sobre la salud de los animales de consumo.

En los resultados de la prueba $\mathrm{T}$ (tabla 24) el nivel de significancia es inferior a $a=0,05$, es decir, existen diferencias significativas entre las respuestas del pretest y el postest. Dos tercios de los estudiantes en el pretest (muy de acuerdo 36\%, y de

\section{TABLA 24. Prueba T. Comparación de medias Estadísticos de muestras y pruebas relacionadas}

\begin{tabular}{|c|c|c|c|c|}
\hline & $\frac{.00}{\frac{0}{0}}$ & $z$ & 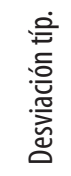 & 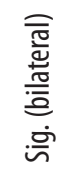 \\
\hline $\begin{array}{l}\text { Creo que conocer sobre } \\
\text { la forma de procesar los } \\
\text { productos animales y ve- } \\
\text { getales me permitirá elegir } \\
\text { cuáles consumo }\end{array}$ & 2,16 & 200 & 1,17 & \multirow[t]{2}{*}{0,00} \\
\hline $\begin{array}{l}\text { Prefiero los derivados de } \\
\text { animales no procesados }\end{array}$ & 3,20 & 200 & 1,42 & \\
\hline
\end{tabular}


acuerdo 30\%, tabla 23) dicen que conocer la forma de procesar los productos animales y vegetales les permite elegir su consumo. En el postest, el 13,5\% (muy de acuerdo) y 22,5\% (de acuerdo) dicen que prefieren los no procesados; la indiferencia en consumir procesados y no procesados se mantiene (23\%) y aumenta quienes dicen estar en desacuerdo $(4,5$ a $16 \%$ ) y muy en desacuerdo ( 5 a $22,5 \%$ ). Algunos estudiantes siguen prefiriendo los productos procesados como las salchichas, el jamón, el salchichón, el chorizo, la mortadela; otros, en cambio, consideran más sano consumir los productos de las carnes y los lácteos sin transformarlos. Los hábitos alimenticios son difíciles de cambiar en las poblaciones porque la influencia cultural y familiar es fuerte; el cambio se logra con la creación de necesidades, con la utilización de otras estrategias didácticas como las películas y los reportajes, así como con la información y el intercambio de experiencias con las familias en las escuelas de padres.

\section{Conclusiones}

Las estrategias didácticas antes, durante y después de la visita al parque temático en contextos no formal e informal contribuyeron a la motivación del aprendizaje lo cual influye en el cambio de actitudes en la mayoría de los estudiantes.

Los parques temáticos son escenarios que permiten aportaciones al proceso de enseñanza-aprendizaje, y contribuyen al trabajo de los temas en contextos formales en el aula y el colegio, de tal forma que el profesor y los estudiantes intercambian sus experiencias antes, durante y después de las visitas guiadas en un tema o temas determinados del plan de estudios.

Algunos estudiantes, después de la visita a Panaca y las clases en el aula, lograron cambiar positivamente sus actitudes de aprendizaje de las ciencias, aspectos importantes en una región eminentemente agraria, para que los futuros ciudadanos tengan pertenencia regional y comprendan la importancia de la acción agraria y el cuidado del ambiente.

La utilización de estrategias didácticas en contextos no formales atrae la atención del estudiante como en el caso específico del parque temático, donde encuentra información directamente de quienes brindan la guía y permiten la interacción. Esas experiencias se fijan en el conocimiento y son evocadas y utilizadas fácilmente en las situaciones que lo requieran, lo cual implica el aprendizaje y el interés en la información; además, el conocimiento genera cambio de actitudes positivas hacia el aprendizaje de las ciencias.

La generación de necesidades y conocimientos claros sobre las diferentes temáticas de las ciencias contribuye a la educación de las actitudes hacia el aprendizaje, siempre y cuando los estudiantes tengan la motivación, el interés y la voluntad de hacerlo.

Las actitudes positivas hacia el aprendizaje de las ciencias por los conocimientos previos que poseen los estudiantes se pueden convertir en comportamientos, si se reconoce la importancia del ambiente sano para la supervivencia del ser humano en un entorno con respeto por la naturaleza.

El aprovechamiento didáctico de la temática de un lugar (parque o museo de ciencias) que permita la interacción de los estudiantes, es un excelente recuso para el profesor, que le ayudará para desarrollar las clases en forma diferente a la tradicional, puesto que las experiencias directas se recuerdan fácilmente, y motiva a indagar y participar fuera $y$ dentro del aula en forma agradable generando aprendizajes significativos.

En los contextos no formales los estudiantes se motivan e interesan por temas que posiblemente en el contexto educativo formal no les hubiesen parecido interesantes, porque el solo hecho de salir del ambiente rutinario de la clase formal crea expectativas que a través de la experiencia directa recuerdan con agrado, creando actitudes positivas hacia el aprendizaje de la ciencia.

Se observa que las actitudes sí cumplieron el proceso de difusas a diferenciadas, como lo sugiere Ponce (1981), porque los estudiantes que tenían actitudes positivas se transformaron y manifestaron conocimientos, convicciones y criterios, así como 
también sentimientos, necesidades y acciones referidas al aprendizaje de las ciencias naturales; es aquí donde los tres componentes de las actitudes: lo cognitivo, lo afectivo y lo conductual se conjugaron para producir la actitud.

\section{Referencias}

Ausubel, D. P., J. D. Novak y H. Hanesian (1983). Psicología Educativa: Un punto de vista cognoscitivo. 2 ed. México: Trillas.

Bujeda, J., J. Carrasquer et ál. (2004). Complementaciones curriculares coherentes con la educación formal. Un ejemplo: el agua. Teruel: Centro de Educación Secundaria Las Viñas.

Díaz, F. D. y G. Hernández (1998). Estrategias docentes para un aprendizaje significativo. Una interpretación constructivista. México: Mc Graw Hill.

Fensham, P. J. (2004). Beyond Knowledge: Other Scientific Qualities as Outcomes for School Science Education, en R. M. Janiuk y E. Samonek-Miciuk (eds.), Science and Technology Education for a Diverse World - dilemmas, needs and partnerships. International Organization.

Fishbein-Ajzen (1980). Understanding attitude and predicting social behavior. New York: Prentice Hall.

Gardner, P. L. (1996). The dimensionality of attitude scales: a widely misunderstood idea. International Journal of Science Education, 18 (8), 913-919.

Guisasola, J. y M. Morentin (2007). ¿Qué papel tienen las visitas escolares a los museos de ciencias en el aprendizaje de las ciencias? Una revisión de las investigaciones. Enseñanza de las ciencias, 25 (3), 401-414.

Guisasola, J., J. Solbes, J. I. Barragués, A. Y. Moreno, M. Morentin (2009). Student understanding of the Special Theory of Relativity and design for a guided visit to a science museum. International Journal of Science Education, 31 (15), 2085-2104.

Hodson, D. (1985). Philosophy of science, science and science education. Studies in Science Education, 12, 25-57.

León Urquijo, A. P. et ál. (2006). Estudio actitudinal en salud ambiental de estudiantes de $5^{\circ}$, $6^{\circ}, 7^{\circ}, 8^{\circ}$ y $9^{\circ}$ de la Educación Básica y $10^{\circ}$ y $11^{\circ}$ de la Educación Media del Departamento del Quindío. Revista Docencia Universitaria, 7, 39-63.

Lillo, J. (2002). Los recursos didácticos en la formación del profesorado de ciencias Experimentales. En Alberto Pazo y J. L. García Soidán (eds.). Los recursos en la formación del profesorado. Aproximación pluridisciplinar. Servicio de Publicaciones Universidad de Vigo.

Lillo, F. y J. Lillo (2002). Using historical events to develop ethical and aesthetic attitudes. En V. Mayer (ed.). Global Science Literacy. Dordrecht, Boston, London: Kluwer Academic Publishers.

Londoño, G., J. Y. Solbes, J. Guisasola (2009). Aprovechamiento conceptual y actitudinal de las visitas a un parque temático. Didáctica de las Ciencias Experimentales y Sociales, 23, 71-92.

Murphy, C. y J. Beggs (2003). Primary pupils' and teachers' use of computers at home and school. British journal of educational technology, 34 (1), 79-83.

Osborne, J., R. Driver y S. Simon (1998). Attitudes to science: Issues and concerns. School Science Review, 79, 27-33.

Ponce, J. R. (1981). Dialéctica de las actitudes en la personalidad. La Habana: Científico Técnica.

Pozo, J. I. y M. A. Gómez (1998). Aprender y enseñar ciencia. Madrid: Morata.

Simpson, R. D. et ál. (1994). Research on the affective dimension of science learning. En D. L. 
Gabel (ed.). Handbook of Research on Science Teaching and Learning. New York: McMillan Pub Co.

Pro, A. de (2005). Presentación de la monografía: La enseñanza no formal de las ciencias. Alambique, 43, 5-8.

Simpson, R. D. y K. M. Troost (1982). Influences on commitment to and learning of science among adolescent students. Science Education, 66 (5), 763-781.

Solbes, J. (2009). Dificultades de aprendizaje y cambio conceptual, procedimental y axiológico (II): nuevas perspectivas. Revista Eureka sobre Enseñanza y Divulgación de las Ciencias, $6(2), 190-212$.

http://www.apac-eureka.org/revista/Volumen6/ Numero_6_2/Solbes_2009b.pdf

Solbes, J., Lozano y R. García (2008). Juegos, juguetes y pequeñas experiencias tecnocientíficos en la enseñanza aprendizaje de la física y química y la tecnología. Investigación en la escuela, $65,71-88$.

Solbes, J., R. Montserrat y C. Furió (2007). El desinterés del alumnado hacia el aprendizaje de la ciencia: implicaciones en su enseñanza. $D i$ - dáctica de las Ciencias Experimentales y Sociales, 21, 91-117.

Solbes, J. y A. Vilches (1989). Interacciones cienciatécnica-sociedad: un instrumento de cambio actitudinal. Enseñanza de las Ciencias, 7(1), 14-20.

Solbes, J. y A. Vilches (1997). STS interactions and the teaching of physics and chemistry. Science Education, 81 (4), 377-386.

Solbes, J. y M. Traver (2003). Against negative image of science: history of science in the physics \& chemistry Education. Science \& Education, 12, 703-717.

Summers, G. (1986). Medición de las actitudes. 4 ed. México: Trillas.

Vazquez, A. y M. A. Manassero (2008). El declive de las actitudes hacia la ciencia de los estudiantes: un indicador inquietante para la educación científica. Revista Eureka sobre Enseñanza y Divulgación de las ciencias, 5(3), 274-292.

Wagensberg, J. (2007). El gozo intelectual. Barcelona: Tusquets.

http://www.apac-eureka.org/revista/Volumen6/ Numero_6_2/Solbes_2009b.pdf 